\title{
Corruption and Health Sector Performances in West Africa Countries: A Theoretical Analysis
}

\author{
Timothy Oladayo Popoola ${ }^{1}$ \\ ${ }^{1}$ Department of Economics, Ahmadu Bello University, Nigeria \\ Correspondence: Timothy Oladayo Popoola, Department of Economics, Ahmadu Bello University, Zaria, \\ Nigeria. Tel: 234-(0)813-5745-100. E-mail: poladayo@gmail.com
}

Received: March 17, 2018; Accepted: April 9, 2018; Published: April 25, 2018

\begin{abstract}
The fact that corruption has become one of the most notoriously persistent and progressively worsening social and welfare problems afflicting virtually all economic processes today is indisputable; while critics of corruption have long argued that corruption reflects government failure in providing health development infrastructures. This paper however provided the basis of theoretical interrelationships between corruption and health sector performances in West African countries. The paper also examines various policies measures as employed by other nations as lessons to improve the performances of health sector in these countries. One implication of these results as evidenced from Singapore, Hong Kong and Tunisia, is that attainment of stronger and effective institution and good governance will lower corruptive practices and improve health sector performances in West Africa nations. The paper therefore calls on governments of West African countries to concentrate on strengthening their institutions especially by reducing corruptive practices and promoting accountability, integrity and transparency in health sector.
\end{abstract}

Keywords: Corruption, Health Sector Performances, West Africa Countries

\section{Introduction}

Corruption, commonly defined as misuse or abuse of public office for private gain (World Bank, 1997), is widely seen today as threat to democratic regimes not only to developed societies such as Europe, America, and Japan, but also developing countries (Iyanda, 2012). Corruption is unlawful use of official power or influence by an official of the government (or agents of the public) either to enrich oneself or further one course and/or any other person at the expense of the public, in contravention of his oath of office and/or contrary to the conventions or laws that are in force. Most often, corruption come in various forms and in a wide array of illicit behavior, such as, bribery, extortion, fraud, nepotism, graft, theft, embezzlement, and falsification of records (Balbra \& Medalla, 2006). If this is unchecked, the creeping accumulation of seemingly mirror infractions of corruptive practices can slowly erode political legitimacy to the point where even non-corrupt officials and members of the public see little point in playing by the rules (World Bank, 1997, p 102).

Notably, healthy citizens often play a crucial role in economic development process as it constitutes an important component of human capital and labour force participation (Linden and Ray, 2017). However, Lavallee, Mireille and Roubaud (2008) observe that most countries in Africa are lagging behind in achieving the United Nations' Millennium Development Goals particularly those which concerns health performances. Evidence of this might be as a result of corruptive practices in the continent which has greatly undermines the provision of health infrastructures. Osoba (1996:372) further sees corruption as anti-development behavior by individual or social group which confers unjust or fraudulent benefits on its perpetrators, and inconsistent with the established legal norms and prevailing moral ethos. This also likely to subvert or diminish the capacity of the legitimate authorities to provide fully for the well-being of the members of the society in a just and equitable manner. Similarly, it engendered deterioration of infrastructure and provision of health facilities (Alemika, 2012:35). Evidence reveals that West Africa nations' health indicators are lower than the global averages. For example, in every single day, Nigeria loses approximately 2,300 under-five year olds children which makes the country the second largest contributor to under-five mortalities worldwide after Republic of Chad (UNICEF, 2016; World Bank, 2017).

Another worrisome issue is the high prevalence of; malaria, cholera, acute hepatitis E, stroke, hypertension, typhoid, meningitis, and all forms of cancer in West African countries (WHO, 2017). These perhaps explains why West Africa nations were far from reaching the health-related targets of the recent past Millennium Development 
Goals (Novignon et al. 2015; and WHO, 2015). Therefore, the focus of this study is not only to provide theoretical explanations on the effects of corruptive practices in health sector performances with evidence from West Africa countries, but also aimed for policy responses to increase efficiency of the sub-region's health sectors with evidence from other nations. The framework of achieving these objectives is presented in four sections. The second section provides theoretical reviews, evidence of corruption as a failure of governance and corruption in West Africa countries and theoretical analysis of corruption and health sector performances in the sub-region of Africa; while section three highlights success policies as employed by other nations. And four presents recommendation and conclusion.

\section{Literature Reviews}

\subsection{An Overview of Corruption in West Africa countries}

Conceptually, corruption can be viewed through more than simple cases of unethical government officials taking money from the public purse for their private benefits; but also the dysfunctional activities in the economy. Generally, it satisfies:

$$
\boldsymbol{C}=\boldsymbol{M}+\boldsymbol{D}-\boldsymbol{A}
$$

where $M$ is monopoly of power or privileges, $D$ is discretion and A is accountability. Notably, corruptive practices (C) abound when agents monopolized power with little or no accountability to the public. In another dimension, United Nations Development Programme (1999) modifies equation (1) with the inclusion of integrity (I) and transparency (T). This suggests that;

\section{Corruptive practices $=(M+D)-(A+I+T)$}

Therefore, as equation 2 indicates, absence of $\mathrm{A}$, I and $\mathrm{T}$ in any country (primarily as a consequence of weak institution) might make the resources meet to provide health facilities to concentrated on small portion of the populace (Balbra and Medalla, 2006). This further suggest that strong institutions often play an important role in development process that concern health sector performances. In another words, it requires highest standards of integrity and transparency (Balboa and Medalla, 2006). The constraints of health financing are largely governance issue because decisions on how much public funds to allocate for health sector vis-à-vis other competing needs are authoritative decisions by agents of the public in government (Eno, 2011). Again, quality and quantity of health workers concerns governance in the sense that government has a role in training health workers, providing good working conditions, and equipping public health facilities.

Evidence from West Africa countries suggest that corruptive practices seem to become way of life and principal method of accumulation of wealth (Mulinge and Lesetedi, 2002). As Alemika (2012) put it, corruption has been institutionalized and normalized as an activity of government and widely entrenched in and tolerated by sectors of society (including the health sector) which are supposed to be the conscience of the society. Therefore, it has become a major impediment to political, economic and social development in most developing countries (Mulinge and Lesetedi, 1998; Osoba, 1996), whereby resulting to increase in poverty, misery, unemployment and degradation of the mass of the social amidst the accumulation of immense wealth by the agents of the society. Historically, the genesis of corruption in West Africa nations might be a consequence of her colonialism (Note 1) (Alemika, 2012 and Andvig, 2009). The augment suggests that, corruption could be traced to the region's colonial history.

\subsection{Theoretical Analysis}

The role of theories in providing basis for analysis can never be over-emphasized. For instance, rational choice theory assert that human beings behave rationally, either in the narrow sense of rational self-interest, that is, the traditional motivator for homo economicus (Note 2) (Hooker, 2011) or in the broader sense based on preference (Coleman, 1990). The first view sees agents of the public as self-interested (Note 3) economic calculation rather than a value system of loyalty to the society. Even in the writings of Mandeville (1728), the flourishing of selfinterest serves as only motive of human actions with the claim that entire system of economic theory can be deduced from one essential axiom of rationality (economic man maximizes his/her utility).

This evidenced that the pursuit of self-interest is the only thing that rational economic actors can do, and anything else is irrational. However, Frank (2005) pointed out that the narrow self-interest model is self-fulfilling and limited, because it encourages the expectation of worst in agents. While the broader view of the theory explains that individual acts purposely towards a goal, which is shaped by their values and preferences (Coleman, 1990). Man in this line of view constantly trying to avoid pains but to gain pleasure. While pleasure and pain are the basis 
for the concept of utility, and since utility is the ultimate end of human actions, then, any human behaviour can be reduced to the behaviour of utility maximization. Logically, therefore healthy living is desired by humans because it generates utilities (pleasure).

Hence, the preference for healthy living can be structure using simple utility function:

$$
U_{i}=U_{i}\left(q^{*}, x_{i}{ }^{o}-x_{i}\right)
$$

where individual utility $i$ is $\left(U_{i}\right), q^{*}$ is vector of commodities in-take (balance-diet, pollution, alcohol consumption, and tobacco), $x_{i}^{o}$ represent the total amount of time available to individual $i$ and $\mathrm{x}_{\mathrm{i}}$ the amount of labour services supplied by individual $i$ for economic activities, while $x_{i}{ }^{o}-x_{i}$ represent leisure time (non-economic activities) of individual $i$. Limitation in access to effective healthcare services might constrain amount of time available for economic activities $\left(x_{i}^{o}\right)$, amount of labour services supplied by individual $\left(x_{i}\right)$, leisure time of individual $\left(x_{i}^{o}-x_{i}\right)$, and pleasure required by individual $i\left(U_{i}\right)$ to function efficiently in the society. Thus, every economic agent considers utilization of health care facility a rationalized choice, and perhaps the best available alternative course of action to achieve their daily economic activities. The theory is important to the heart of this paper because it helps to understanding health seeking behavior of individual and selfish interest of others (those who supply fake drugs, substandard equipment, sharing of unallocated budget funds, and inflation of contracts) in West African countries.

Furthermore, the principal-agent theory that has its roots in information economics is important to this analysis. The theory emphasis is on the conflicting mechanisms that limit agents' self-serving and corruptive behavior (Jensen, 1983, p 326). It arises when two (or more) parties with one, designated as the agent, acts on behalf of, or serve as representative for other, the public, in a particular domain of decisions (Ross, 1973, p 134). Principalagent relationship can be characterized by principals or public (ill-informed) and agent (informed individual), who are attempting to maximize their utility functions (Neuman, 2007). Using utility function to formalizes this theory, where $U_{A}$ and $U_{P}$ represents the utility functions of agents of health sector and principal (citizen) in West Africa countries respectively. Assuming both is acting so as to maximize their expected utility (even with corruptive practices) and agents' choices are under uncertainty. The agents might choose an act, $\mathbf{a}$, where $\mathbf{S}$ is the feasible action space. Supposing the random payoff from corruptive practices is $\mathbf{w}(\mathbf{a})$, which might depend largely on the effectiveness of institution $(\boldsymbol{\theta})$.

Thus, the performance of the agents is generally the function of the payoff from their corruptive acts and quality of the institution ( $\boldsymbol{\theta})$. Mathematically,

$$
U_{A}=U_{A}[w \text { (a), subject to } \theta]
$$

There are two possibilities; the first is if the payoff from corruptive acts (a) is greater than the punishment from weak institutions $(\theta)$, rational agents would be corrupt. But if this payoff is less than the punishment, rational agents would concern societal welfare in policies making. Usually, agents act in such a way to:

\section{Max. $E\left\{U_{A}[w\right.$ (a) subject to $\left.\theta]\right\}$}

Here the agent takes the expectation over his subjectively held probability distributions and the solution to the agent's problem involves the choice of an optimal act, $\mathbf{a}^{\mathbf{0}}$, conditional on the particular expectation mapping from the space of feasible actions.

For principals, their optimal utilities $\left(\mathrm{U}_{\mathrm{P}}\right)$ depend on $\mathbf{a}^{\mathbf{0}}$ actions and quality of institution $(\boldsymbol{\theta})$ to control corruption in health sector. Hence:

$$
U_{P}=U_{P}\left(a^{o} \text {, subject to } \theta\right)
$$

If the principals have complete information about $\mathbf{a}^{\mathbf{0}}$, they will choose to:

$$
\text { Max. } E\left\{U_{P}\left[a^{o} \text {, subject to } \theta\right]\right\}
$$

However, conflict might emerge when principals have to count on another party, the agent, to perform activities or services on their behalf to maximize their utilities, especially when principals are unable to verify agent's actions or when their performances could not be easily evaluated, the agents might have the opportunity to favour his own interest (or achieve highest $\mathrm{U}_{\mathrm{A}}$ possible) over that of the principals $\left(\mathrm{U}_{\mathrm{P}}\right)$. Following from above, both parties have different interests but similar objective of maximizing their independent utility function, however, the theory is important to this study because it helps to identify those corruptive practices of agents might induce them to undertake actions that might constraint health sector performances in West Africa nations.

Another theory is good governance theory that argues for new paradigm of "good governance" to ensure citizen freedom, empowerment, to encourage creativity, enhance transparency, and to ensure accountability in the 
economy. This theoretical argument was that democratic accountability reduced the possibility of corruptive practices and rent seeking, this in turn enabled a rule of law and stable property rights to be enforced, and these were also essential for reducing transaction costs in health sector, and thereby allowing economic growth. Bang and Esmark (2009) opined that the theory relies on instruments that can strategically utilizes and nurtures selfgoverning potential of civil society under the strategic supervision of public institutions which are seen in diverse areas, such as: employment policy, health care provision policy, educational policy and all other policies that can ensures effectiveness of the economy.

The theory drew on new political economy theories that supported democracies on the ground that they helped to establish property rights and reduced rent seeking. Although, the theory explains political-administrative way of making public policy, reforming and organizing, it does not empirically explain bad governance and it influencing consequences on health care service delivery. However, the theory is highly critical to ensure regulatory efficiency in West African health sector, with evidence from Stoker (2002, p 17-18) study that opined that governance styles and potential for contracting, and new firms of regulation is highly important, because it ultimately concerned with the creating of conditions for ordered rule and collective action (Peters and Pierre, 1998) even in health sector performances.

To ensure healthy society, the model of Grossman (1972) explained that health care service delivery in any economy is determined by numerous factors including, social class, work environment, employment status and income, housing conditions, pollution, education, diet and lifestyle. The model was developed from neoclassical theory of choice which emphasizes that health serve as fundamental commodity for every individual to function effectively in the society. Individual allocates their resources to produce health, which implies that the demand for healthcare is a derived demand.

The Grossman model (1972) was modified by Mwabu (2007). In this modification, the household's preference ordering over health, $\mathrm{H}$, and vector of other goods and services, $\mathrm{Z}_{\mathrm{i}}$, that affect healthy living of households can be characterized by a utility function subject to household income $\left(\mathrm{W}_{\mathrm{i}}\right)$ and gross investment in health $\left(\mathrm{I}_{\mathrm{i}}\right)$.

$$
\operatorname{Max} U=U\left(\varphi_{i}, H_{i}, Z_{i}\right)
$$

Subject to:

$$
\begin{gathered}
P_{i} M_{i}+V_{i} X_{i}+W_{i}\left(T L_{i}+T H_{i}+T_{i}\right)=W_{i} \Omega+A_{i}=R \\
I_{i}=I_{i}\left(M_{i}, T H_{i}, E_{i}\right) \\
I_{i}=\left(H_{i}-H_{o}\right)+\delta H_{i} \\
Z_{i}=Z_{i}\left(X_{i}, T_{i}, E_{i}\right)
\end{gathered}
$$

where, $H i$ is the stock of health in period $\mathrm{i}$ (time period $\mathrm{i}=1$ for all variables); $\varphi i$ is the flow of services per unit of health stock so that $h i=\varphi i H i$ is the total quantity of health services available for consumption in period i, measured in this case by the number of healthy days; $H_{\mathrm{O}}$ is inherited stock of health capital, and $\delta \mathrm{i}$ is its depreciation rate in period i; $P i$ and $V i$ are prices of medical care $(M i)$ and other goods $(X i)$ respectively; $W i$ is the wage rate in the labor market; $I i$ is gross investment in health; $Z i$ is an aggregate of all commodities besides health; $T H i$ and $T i$ are time inputs associated with the production of $I i$ and $Z i$; TLi is the time lost from market and non-market activities due to illness; $E i$ is level of education; $A$ i is non-labor income; $\Omega$ is total the amount of time available in any period; $R$ is full income, the monetary value of assets plus the earnings an individual would obtain if he spent all of his time working.

Equation $8 \mathrm{~b}$ is the full household income constraint, where:

$$
\mathbf{\Omega}=\boldsymbol{T} \boldsymbol{W}_{i}+\mathrm{TL}_{\boldsymbol{i}}+\mathrm{TH} \boldsymbol{H}_{\boldsymbol{i}}+\mathrm{T}_{\boldsymbol{i}}
$$

Where; $T W_{1}$ is hours of work. The inclusion of $T L \mathrm{i}$ in (8b) modifies Becker's (1965) time budget constraint, so that it can fully exhaust the total time available in any period (Grossman, 1972). Part of the 'full income, $R$ ', a concept coined by Becker (1965), is spent on market goods, while part of it is spent on non-market production, and the remaining part is lost due to illness.

Equation $8 \mathrm{c}$ and $\mathrm{d}$ are production functions for health and a composite non-health community respectively. The lagrangian function to be maximized is:

$$
\boldsymbol{\ell}=\boldsymbol{U}\left(\varphi_{i} H_{i}, Z_{i}\right)+\lambda\left[R-\left(C_{i}+C_{1 i}+W_{i} T L_{i}\right)\right]
$$

where, $C i=P i M i+W i T H i$ (Total cost of medical care); $C 1 \mathrm{i}=V i X i+W i T i$ (Cost of non-medical commodities); and $H i-H O=I i$ (Gross investment in health, with its arguments $M$ and $T H$ suppressed) and with depreciation rate $\delta \mathrm{i}$ set equal to zero. The optimal quantity of health capital demanded, $H$, is found by differentiating equation $9 \mathrm{~b}$ 
with respect to gross investment $(I)$ and setting the partial derivatives equal to zero to obtain the first order condition (FOC), which after manipulation yields the equilibrium condition. Hence, the emphasis of this analysis is that individual and household often choose the optimal amount of $\mathrm{H}_{\mathrm{i}}$ that they need so as to produce healthy days, because reduction in the number of healthy days lost to illness $\left(\delta T L_{i} / \delta H_{i}\right)$ can constraint economic outcomes. In other words, health status is governed by health investment $\left(I_{i}\right)$ but constrained by corruption.

To Galama and Hans (2013), Grossman model and its extensions explain many salient stylized facts on health inequalities. However, the theoretical shortcomings of the model are: (i.) emphasizes that individual would invest in health until the marginal benefit of health equals its marginal cost (Cost-Benefit Analysis); (ii.) the length of individual's life would be determined endogenously (Rok, 2012). In spite of these, the model helps this study to understand that capital depreciation replacement and timely investment in health sector would enhance healthy living in sub-Saharan African countries, but corruptive practices limit its performances.

Table 1. Corruption-Health Performances Nexus

\begin{tabular}{cccc}
\hline WEST AFRICA COUNTRIES EXPERIENCES & \multicolumn{2}{c}{ HEALTH SECTOR PERFORMANCES } \\
\cline { 3 - 4 } & & GOOD & BAD \\
\cline { 3 - 4 } CORRUPTION & HIGH & B & A \\
\hline
\end{tabular}

Sources: Author's initiatives, 2017

Table 1 suggests the nexus between corruption and health performances in West Africa countries. Section A indicates bad health sector performances when corruptive practices are very high. The section is also characterized by pursuit of self-interest in attempting to maximize individual welfare $\left(I_{w}\right)$ at the expense of social welfare $\left(S_{w}\right)$. On the other hand, good health sector performances are expected while corruptive practices are very low in any economy, as represented by section $\mathrm{B}$.

\section{Lessons for West African Nations}

The link between corruption and health sector performance is clear from above explanations. However, lessons can be drawn from some countries' experiences:

\subsection{Singapore}

Today Singapore ranks sixth in the world in healthcare outcomes even well ahead of many developed countries, including the United States (Haseltine, 2013). What was the philosophy and what were the key decisions that drove this transformation? The answers are bigger than just the process of putting a healthcare system together. Importantly, there are larger factors that have made these to work for the nation. These factors include; the way Singapore is governed, how her government approaches domestic issues, the spirit and philosophy of the country itself, and how it deals with corruption. As Haseltine (2013) noted, three factors enabled these successes, they include, the nation's long-term political unity, her ability to recognize and establish national priorities and the consistent desire for collective well-being and social harmony of the nation. For example, an early move was to bring primary healthcare services closer to the people especially those in the rural part of the nation.

The government of Singapore also upgraded the infrastructure at all public hospitals dated from the Second World War. Health facilities were also improved, while more investments were made in modern equipment. Since her independence, ambitious hospital construction and expansion programmes were also taken place. The government also provides subsidies to certain private institutions and voluntary welfare organizations to provide healthcare services to the elderly citizens, chronically sick people, and mentally ill-individuals. In addition, Singapore also introduces individual medical savings plan called Medicare. The plan is similar to Nigerian pension funds monthly contributions where citizen of Singapore especially workers contributes a certain percentage (set by the government) to their individual accounts, as do their employers. The money can then be used to pay for health services as well as health insurance plans.

The establishment of Corrupt Practices Investigation Bureau (CPIB) in 1952 as the sole agency responsible for combating corruption in Singapore makes control of corruption the top of the government agenda. Presently, the nation ranked $5^{\text {th }}$ less corrupt nation among the 177 countries in the world, and the most transparent country in Asia (Transparency International, 2013). The lessons from Singapore should therefore be of interest to West African countries in planning the future of healthcare in this region, for Singapore was not always rich as other countries such as, the United States of America. 


\subsection{Hong Kong}

Hong Kong also has very impressive health indicators. The Health Facts of Hong Kong (2015) reveals that the life expectancy for male and female in the nation are 81.2 and 86.7 years at birth respectively; while the country has only 4.9 maternal mortality rates per 100,000 live births and 1.7 per 1,000 live birth for Infant Mortality Rates.

Table 2. Key Health Professionals Numbers in Hong Kong (as at 2015)

\begin{tabular}{llll}
\hline & \multicolumn{2}{l}{ Total Number } & \multicolumn{2}{l}{ Healthcare Professional to population ratio } \\
\cline { 2 - 4 } & $(2015)$ & Hong Kong & WHO recommendations for all nations (2006) \\
\cline { 2 - 4 } Medical Doctors & 13,417 & $1: 541$ & $1: 700$ \\
Nurses & 48,047 & $1: 151$ & $1: 1,000$ \\
\hline
\end{tabular}

Sources: Health Facts of Hong Kong, 2015

The table 2 indicates the ratio of medical doctors and nurses to citizens of Hong Kong as at 2015. Against the one doctor to maximum of 700 citizens and one nurse to maximum of 1,000 populations recommended by WHO (2006), the table reveals that Hong Kong has even more improve records of access to quality healthcare services over the years. In the last 25 years of Hong Kong, all her citizens are eligible to full access public healthcare services, and strengthening basic healthcare services has been the focus of Hong Kong's government over the recent years. However, the secret besides these health sector performances is as a result of transparency in health facilities financing which make the Transparency International to rank Hong Kong $15^{\text {th }}$ less corrupt nation in the world (Transparency International Corruption Perceptions Index, 2013).

\subsection{Tunisia (North Africa)}

The life expectancy at birth of average Tunisian in 2012 was 76 years. The country has only 56 maternal mortality rates per 100,000 live births in 2010, and rural Tunisia's population using improved drinking-water sources and sanitation facilities are 89 and 75 per cent respectively in 2011 (Global Health Observatory, 2014). Evidence reviewed in Habiba and Grenier (2009) study revealed that Tunisia has the best health indicators among all countries in Africa. The authors attributed this to number of factors including large numbers of qualified medical specialists, strong public and private health facilities, good medical equipment and high level of services. For example, nearly 90 per cent of Tunisia's citizens have access to health insurance that provides a relatively high level of basic healthcare services, where the health insurance coverage is funded through employee contributions and government-subsidized cover for those who are poor and unemployed. The high health sector performances of Tunisia might be as a result of less predatory corruption as well as political and economic disenfranchisement in the country as Transparency International Corruption Perceptions Index (2013) ranks Tunisia $77^{\text {th }}$ less corrupt among 177 nations of the world. For decades, Tunisia has been considered one of the success stories on the African continent with sound macroeconomic alongside impressive social management accomplishments which set the nation apart as one of the most robust performers in Africa (ADB, 2011).

\section{Policy Issues and Recommendations}

A critical aspect of strengthening health sector in West Africa nations lies with improved governance, strong institutions and value-oriented societies and households. The health professionals themselves also need reorientation as partners of progress. There should be a merit-based recruitment, promotion, adequate compensation and accountability of performances of all health providers and her policy makers. Sanctions against corruption should be enhanced to ensure transparency in health facilities provision and infrastructure development.

According to Rocamora (1997) cited in Balboa and Medalla (2006), control of corruption requires three strategies, first, the formal machinery of monitoring agents (of public) and politicians needs to be drastically improved and implement all measures to enhance the health sector performances in SSA nations. Second, there should be a political will, which must be generated by citizens' welfare needs. Third, the public should be educated to exert moral and political pressure to outlaw corruption. The mobilization of such political pressure depends on a clearer understanding of modern concepts of public office and public service and a more widespread awareness of social costs and political risks which corruption entails.

\subsection{Conclusion}

Corruption undermines the provision of health facilities. As evidenced from Singapore, Hong Kong and Tunisia, good governance plays important role in economic development process of providing quality health infrastructures 
to improve health sector performances in West Africa nations. More so, the public must be educated to exert moral and political pressure to outlaw corruption in health sectors.

\section{References}

African Development Bank. (2011). The Revelation in Tunisia: Economic Challenges and Prospects, p. 5.

Alemika, E. O. (2012). Corruption and insecurity in Nigeria, Nigeria, Proceedings of the ABU@50Humanities International Conference, ABU Zaria

Andvig, J. C. (2009). Corruption in sub-Saharan Africa and its sources of evidence, Norwegian Institute of International Affairs, Oslo, Norway.

Balboa, J., \& Medalla, E. M. (2006). Anti-corruption and Governance: The Philippine Experience, Asia-Pacific Economic Cooperation, Viet Nam 23-24 May, 2006

Becker, G. S. (1964). Human Capital, New York: National Bureau of Economic Research.

Coleman, J. (1990). Foundations of Social Theory, Cambridge MA: Harvard University Press.

Corrupt Practices Investigation Bureau (1952).

Eno, V. B. (2010). Governance Constraints and Health Care Delivery in Nigeria: The Case of Primary HealthCare Services in Akwa-Ibom State, Public Administration and Management Volume 15(2), 342-364

Galama, T., \& Hans, K. (2013). Health Inequalities through the Lens of Health Capital theory, Rand Labour and Population.

Global Health Observatory. (2014)

Grossman. (2003). Grossman's Theory of the Demand for Healthcare by Professor Paul Dolan.

Habiba, B. R., \& Grenier, F. R. (2009). Social determinants of health in Tunisia: The case-analysis of Ariana" International Journal for Equity in Health.

Haseltine, W. A. (2013). Affordable Excellence: The Singapore Healthcare story, Washington DC: Brookings Institution.

Health Facts of Hong Kong. (2015 Edition). Retrieved from http://www.censtatd.gov.hk/hong_kong_statistics

Hooker, J. N. (2011). Moral Implications of Rational Choice theories, Tepper School of Business, Carnegie Mellon University, U.S.A.

Iyanda, D. O. (2012). Corruption: Definitions, Theories and Concepts, Arabian Journal of Business and Management Review, 2(4), 37-45. https://doi.org/10.12816/0002257

Lavallee E., R. Mireille and F. Rouband (2008). Corruption and Trust in Political Institutions in sub-Saharan Africa, Dial Development Institutions and Analysis de Long term DT/2008-07.

Lim, J., Himani, T. \& Abeysighe (2010). Singapore's healthcare financing: Some Challenges, Singapore Economic Policy Conference, Hyatt Hotel Singapore.

Mulinge, M. M., \& Lesetedi, G. N. (1998). Interrogating our past: Colonialism and Corruption in sub- Saharan Africa, Africa Journal of Political Science, 3(2), 15-28.

Mulinge, M. M., \& Lesetedi, G. N. (2002). Corruption in sub-Saharan Africa: Towards a more Holistic Approach, Africa Journal of Political Science, 7(2), 51-77. https://doi.org/10.4314/ajps.v7i1.27324

Mwabu, G. (2007). Health Economics for Low-Income Countries, Economic Growth, Center Discussion Paper No 955 .

Neuman, E., \& Neuman, S. (2007). Agency in Healthcare: Are Medical-Care Givers Perfect Agents? IZADP No 2727.

Osuba, S. O. (1996). Corruption in Nigeria: Historical Perspectives, Review of African Political Economy, 69, 371386. https://doi.org/10.1080/03056249608704203

Rok H. (2012). Theoretical Shortcomings of the Grossman Model" Organization and Information in Healthcare, 28(1), 63-75.

Ross, S. A. (1973). The Economic Theory of Agency: The Principal's Problem. National Science Foundation, 63(2), 134-139.

Stoker, G. (2002). Governance as theory: Five Propositions, ESRC Local Governance Research Programme 
Transparency International Corruption Perception Index (2013).

UNICEF. (2013). World Health Indicators.

World Bank. (1997). World Development Report, World Bank, Washington, DC.

World Bank. (2002). World Development Report, World Bank, Washington, DC.

World Bank. (2017). World Bank Development Indicator, World Bank, Washington, DC.

\section{Notes}

Note 1 . The term colonialism has used by this study refer to an international system of economic exploitation in which more powerful nations dominate weaker ones. According to Alemika (2012), there were several corruption scandal and probes during the colonial rule. The scandals were exposed in the administration of colonial administrative machineries.

Note 2. According to Garba (2014:56-57), the conceptual analysis of economic man (homo economicus) in terms of necessary and sufficient conditions: $\mathrm{X}$ is an economic man IFF (i) X has free will, (ii) X has perfect knowledge, (iii) $\mathrm{X}$ is selfish, (iv) $\mathrm{X}$ prefers pleasure to pain, (v) $\mathrm{X}$ chooses independently and (vi) X would choose the most preferred option if that option is available. The last two conditions are equivalent to saying that man is 'an isolated ego, calculating his own advantage' (Earle, 1992:196). This also raises the individual-society problems (Knight, 1935).

Note 3. Ethical questions cited in Garba (2014:57) become obvious: “is selfishness good?" and "is it right for X to be an isolated ego"?

\section{Copyrights}

Copyright for this article is retained by the author(s), with first publication rights granted to the journal.

This is an open-access article distributed under the terms and conditions of the Creative Commons Attribution license (http://creativecommons.org/licenses/by/4.0/). 